\title{
Are Earnings Inequality and Mobility Overstated? the Impact of Non-Classical Measurement Error
}

\author{
Peter Gottschalk and Minh Huynh
}

August 2, 2006

\begin{abstract}
Measures of inequality and mobility based on self-reported earnings reflect attributes of both the joint distribution of earnings across time and the joint distribution of measurement error and earnings. While classical measurement error would increase measures of inequality and mobility there is substantial evidence that measurement error in earnings is not classical. In this paper we present the analytical links between non-classical measurement error and measures of inequality and mobility. The empirical importance of non-classical measurement error is explored using the Survey of Income and Program Participation matched to tax records. We find that the effects of non-classical measurement error are large. However, these non-classical effects are largely offsetting when estimating mobility. As a result SIPP estimates of mobility are similar to estimates based on tax records, though SIPP estimates of inequality are smaller than estimates based on tax records.
\end{abstract}

\section{Introduction}

What is the impact of measurement error on measures of inequality and mobility? Measures of inequality and mobility based on self-reported earnings reflect both attributes of the joint distribution of earnings across time and the joint distribution of measurement error and earnings. Measurement error can, therefore, lead to potentially biased estimates of inequality in the marginal distribution of earnings and estimates of mobility across the joint distribution.

While classical measurement error would lead to upward bias in estimates of inequality and mobility, the evidence reviewed in Bound et al. (2001) shows that measurement error is not classical. Measurement error is mean reverting, in the sense that persons with low earnings tend to overstate their earnings and persons with high earnings understate their earnings. This offsets the inequality increasing effects of classical measurement error. The impact of non-classical measurement error on mobility is less clear since mobility measures are based on the joint distribution of reported earnings in two periods. This introduces the possibility that earnings and lagged earnings suffer from the same form of measurement error and that measurement errors in the two periods are correlated

In this paper we present the analytical links between the statistical properties of measurement error and the properties of standard measures of inequality and mobility. We use 
the Survey of Income and Program Participation (SIPP) matched to tax records to assess the quantitative importance of the qualitative links developed in the analytical section.

The rest of this paper is divided into four sections. The following section reviews the theoretical and empirical literature on measurement error in earnings. We then provide an analytical framework which allows for non-classical measurement error in both earnings and lagged earnings. Section 4 provide estimates of the quantitative importance of the factors developed in the analytical section. In Section 5 we draw conclusions based on these findings.

\section{Review of Literature}

Bound et al. (2001) review the substantial literature on measurement error in earnings. This literature has focused primarily on the implications of measurement error for studies where earnings appear either as a dependent variable or as an independent variable, but not both. As the following section makes clear, a new set of issues arise when studying earnings mobility since mobility measures describe the relationship between earnings in two different periods. As a result, there is potentially measurement error in both dependent and independent variables being studied. This introduces the possibility that the two sources of measurement error are not only correlated with earnings and lagged earnings but that the two sources of measurement error may themselves be correlated .

While the literature on the impact of measurement error has largely focused on single source of measurement error, these studies provide the foundation for our study. The first set of studies to examine the role of measurement error in the PSID were based on a validation study in which a sample of 418 workers in a large manufacturing plant reported their earnings using the same instrument as used in the PSID. Duncan and Hill (1985) analyze the difference between the firm's payroll records for these respondents and the earnings they reported on the PSID questionnaire. Since the firm was highly unionized, it is not surprising that respondents had higher mean earnings and lower variance of earnings than a nationally representative sample of workers. More importantly Duncan and Hill (1985) find that the variance of measurement errors was large even among this group of unionized workers with an explicit contract that specified wages and working conditions. The variance of measurement error is 30 percent as large as the variance of payroll earnings in1981.and 15 percent as large in 1982. Furthermore, the measurement error in this validation study is mean reverting

Bound and Krueger (1991) find roughly as large measurement error when CPS earnings are compared to Social Security Administrative (SSA) records. This and the follow-up study by Bollinger (1998) also find negative correlation between the measurement error and SSA earnings. ${ }^{1}$ Both studies also find positive correlation in measurement error across the two years of matched CPS data

The finding that measurement error is large and mean reverting is corroborated by Bound et al. (1994) who use data from a second wave of data collected from the same firm in the PSID validation study by Duncan and Hill (1985). Since workers had to be continuously working for the same firm, the sample size decreases substantially. But even this sample of workers continuously employed by the same firm over a six year period (1982 to 1986)

\footnotetext{
${ }^{1}$ This mean reversion in reported earnings is largely driven by low-earning males who overstate their SSA earnings.
} 
exhibits the same mean reversion and positive correlation in measurement error six years apart. Furthermore the size of the measurement error is large: the variance of measurement error is 15 to 30 percent as large as the variance of earnings from administrative records plus the variance of measurement error. ${ }^{2}$

These studies, and the wider literature reviewed in Bound et al. (2001), treat earnings from administrative records as being free of measurement error. Abowd and Stinson (2004) develop an alternative approach which allows for measurement error in earnings from administrative records as well as reported earnings.

The two studies most closely related to our study are Pischke (1995) and Dragoset and Fields (2006) who both provide empirical estimates of the impact of measurement error on specific measures of mobility. ${ }^{3}$ Following the literature initially developed in MaCurdy (1982), Pischke examines the impact of measurement error in the PSID validation study on estimates of the variance of permanent and transitory earnings. This earnings components model is estimated in order to assess whether transitory earnings shocks are under-reported in the PSID. Dragoset and Fields (2006) examines the effect of measurement error on measures of different concepts of mobility. Neither study develops a general framework that can be used to examine the impact of non-classical measurement error on a specific set of measures of inequality and mobility.

\section{Analytical Links}

In this section we develop the analytical links between the statistical structure of nonclassical measurement error and summary measures of inequality and mobility. We develop these analytical links by focusing on the joint distribution of log earnings, $E$, and lagged $\log$ earnings, $E_{-1}$. The variances of the marginal distributions provide summary measures of inequality. The conditional expectation function of $E$, given $E_{-1}$, and the correlation between $E$ and $E_{-1}$ provide our summary measures of mobility.

We build on Bound et al. (2001) who considers the impact of non-classical measurement error in a bivariate regression of $E$ on $E_{-1}$, where either $E$ or $E_{-1}$, but not both, are measured with error. This restriction is unlikely to be met in our case since $E$ and $E_{-1}$ are typically obtained from reported earnings in two different years from the same survey. They are, therefore, both likely to be measured with error and these errors are not likely to be classical.

We show that allowing for measurement error in both $E$ and $E_{-1}$ adds several new routes by which non-classical measurement error can affect our measures of mobility. Measurement error in reported earnings may not only be correlated with contemporaneous earnings but measurement error in earnings and lagged earnings may themselves be correlated.

\footnotetext{
${ }^{2}$ See Bound et al. (1994) Table 1 who report the ratio of measurement error to total variation in PSID earnings in 1982 and 1986 to be .151 and .302. Bound and Krueger (1991) develop the relationship between this measure of the relative importance of measurement error to the reliability ratio which they define as $\frac{\operatorname{var}\left(E^{*}\right)}{\operatorname{var}(E)}$, where $E^{*}$ is $\log$ earnings in the administrative data set, $E=E^{*}+v$ is reported log earnings, and $v$ is measurement error.

${ }^{3}$ Coder and Scoon-Rogers (1996) also examines measurement error in the SIPP but does not examine its effect on mobility.
} 


\subsection{Generalized Measurement Error Model}

Following the standard notation consider the following bivariate relationship between $E^{*}$ and $E_{-1}^{*}$

$$
E^{*}=\beta E_{-1}^{*}+\varepsilon
$$

where $E^{*}$ and $E_{-1}^{*}$ are log earnings and lagged log earnings respectively. ${ }^{4}$ Since $E^{*}$ and $E_{-1}^{*}$ are both measured in logs $\beta$ can be interpreted as the intertemporal elasticity of earnings,

Both $E^{*}$ and $E_{-1}^{*}$ are, however, subject to measurement error leading to the observed values of $E$ and $E_{-1}$ :

$$
\begin{aligned}
E & =E^{*}+v \\
E_{-1} & =E_{-1}^{*}+\mu
\end{aligned}
$$

where $v$ and $\mu$ are measurement error.

Within this framework $\sigma_{E^{*}}^{2}$ and $\sigma_{E_{-1}^{*}}^{2}$ provide summary measures of inequality in earnings and lagged earnings. Likewise, the elasticity of earnings with respect to lagged earnings, $\beta$, and the correlation between earnings in the two periods,

$$
\rho=\beta \frac{\sigma_{E_{-1}^{*}}}{\sigma_{E^{*}}}
$$

provide measures of mobility. ${ }^{5}$

\subsubsection{Impact on Measures of Inequality}

The impact of measurement error on inequality in earnings in year $t$ is given by

$$
\sigma_{E}^{2}-\sigma_{E^{*}}^{2}=2 \operatorname{cov}\left(E^{*}, v\right)+\operatorname{var}(v)
$$

where $\sigma_{E}^{2}$ is the variance of measured log earnings and $\sigma_{E^{*}}^{2}$ is the variance of log earnings without measurement error. Equation 5 shows that the difference between the variance of mismeasured log earnings and the variance of of actual log earnings, $\sigma_{E}^{2}-\sigma_{E^{*}}^{2}$, depends both on the variance of measurement error, $\operatorname{var}(v)$, and the covariance of measurement error and earnings, $\operatorname{cov}\left(E^{*}, v\right)$. While larger variance of measurement error will unambiguously lead to an upward bias in inequality, this will be offset by mean reversion in measurement error (i.e. $\left.\operatorname{cov}\left(E^{*}, v\right)<0\right)$. If $\frac{\operatorname{cov}\left(E^{*}, v\right)}{\operatorname{var}(v)}<-.5$ then measured inequality will understate the degree of inequality.

The impact of measurement error on the trend in inequality can be expressed in terms of changes in inequality of reported earnings, $\Delta=\sigma_{E}^{2}-\sigma_{E_{-1}}^{2}$, and changes in inequality of actual earnings, $\Delta^{*}=\sigma_{E^{*}}^{2}-\sigma_{E_{-1}^{*}}^{2}$,

$$
\Delta-\Delta^{*}=2\left[\operatorname{cov}\left(E^{*}, v\right)-\operatorname{cov}\left(E_{-1}^{*}, \mu\right)\right]+[\operatorname{var}(v)-\operatorname{var}(\mu)]
$$

which shows that increases in inequality will be overstated if the variance of measurement error is increasing or if mean reversion in measured earnings is declining.

\footnotetext{
${ }^{4}$ We follow the previous literature by assuming that all conditional expectations are linear in logs. Appendix A provides non-parametric plots which show that this assumption is largely met in our data.

${ }^{5}$ In this paper we consider only measures of mobility based on variances and covariances of earnings and lagged earnings, which include $\beta, \rho$ and the measure developed in Shorrocks (1978)).See Fields (2005) for the effects of measurement error on alternative measures of mobility.
} 


\subsubsection{Impact on Measures of Mobility}

The impact of measurement error on the estimated elasticity, $\hat{\beta}$, can be derived by solving 2 and 3 for $E^{*}$ and $E_{-1}^{*}$ and substituting the result into 1 :

$$
E=\beta E_{-1}+v-\beta \mu+\varepsilon
$$

This implies that the OLS estimate of $\beta$ is given by:

$$
\begin{aligned}
\hat{\beta} & =\frac{\operatorname{cov}\left(E_{-1}, \beta E_{-1}+v-\beta \mu+\varepsilon\right)}{\operatorname{var}\left(E_{-1}\right)} \\
& =\beta+\frac{\operatorname{cov}\left(E_{-1} v\right)}{\operatorname{var}\left(E_{-1}\right)}-\beta \frac{\operatorname{cov}\left(E_{-1} \mu\right)}{\operatorname{var}\left(E_{-1}\right)}+\frac{\operatorname{cov}\left(E_{-1}, \varepsilon\right)}{\operatorname{var}\left(E_{-1}\right)} \\
& =\beta\left(1-\beta_{\mu E_{-1}}\right)+\beta_{v E_{-1}}+\beta_{\varepsilon \mu} \frac{\operatorname{var}(\mu)}{\operatorname{var}\left(E_{-1}\right)}
\end{aligned}
$$

where $\beta_{\mu E_{-1}}=\frac{\operatorname{cov}\left(\mu, E_{-1}\right)}{\operatorname{var}\left(E_{-1}\right)}$ and other coefficients are defined similarly. ${ }^{6}$

It is useful to rewrite 8 in terms of the underlying parameters that capture the nonclassical nature of measurement error: $\beta_{v E^{*}}, \beta_{\mu E_{-1}^{*}}, \beta_{v \mu}, \beta_{v \varepsilon}$ and $\beta_{\varepsilon \mu}$. The first two parameters, $\beta_{v E^{*}}$ and $\beta_{\mu E_{-1}^{*}}$, allow measurement error in $E$ and in $E_{-1}$ to be correlated with the $E^{*}$ and $E_{-1}^{*}{ }^{7}$ The third parameter, $\beta_{v \mu}$, allows measurement errors in $E$ and in $E_{-1}$ to be correlated with each other. Measurement error in $E^{*}$ and $E_{-1}^{*}$ may also be correlated with $\varepsilon$, as captured by $\beta_{v \varepsilon}$ and $\beta_{\varepsilon \mu}$.

In Appendix B we show that equation 8 can be written in terms of these underlying parameters: ${ }^{8}$

$$
\begin{aligned}
\hat{\beta}= & \beta\left(1+\left\{\left(\beta_{v E^{*}}-\beta_{\mu E_{-1}^{*}}\right) \frac{\operatorname{var}\left(E_{-1}^{*}\right)}{\operatorname{var}\left(E_{-1}\right)}\right\}\right) \\
& +\left\{\left(\beta_{v E^{*}}-\beta_{v \varepsilon}\right) \frac{\operatorname{var}(\varepsilon)}{\beta \operatorname{var}\left(E_{-1}\right)}\right\}+\left\{\left[\beta_{v \mu}+\beta_{\varepsilon \mu}-\beta\right] \frac{\operatorname{var}(\mu)}{\operatorname{var}\left(E_{-1}\right)}\right\}
\end{aligned}
$$

This expression shows that the non-classical nature of measurement error in earnings and lagged earnings affects $\hat{\beta}$ through three different channels, indicated by the braces. The first term in braces captures the effect of mean reversion, where $v$ and $\mu$ are allowed to depend on $E^{*}$ and $E_{-1}^{*}$ respectively. Consider the case where measurement error in both earnings and lagged earnings are mean reverting ( i.e. $\beta_{v E^{*}}<0$ and $\beta_{\mu E_{-1}^{*}}<0$ ). The term in braces shows that the net effect of mean reversion depends on offsetting effects of mean reversion in earnings and lagged earnings. If there is equal mean reversion in earnings and lagged earnings then $\beta_{v E^{*}}=\beta_{\mu E_{-1}^{*}}$. In this case the term in braces is zero and mean reversion affects inequality but not mobility as measured by $\hat{\beta}$. If earnings and lagged earnings are obtained from the same survey instrument, administered in two different years,

${ }^{6}$ Like Bound and Krueger (1991) we do not distiguish between sample and population coefficients since any bias from measurement error does not depend on $N$.

${ }^{7}$ Since $E_{-1}=E_{-1}^{*}+\mu$, there is a built in correlation between $E_{-1}$ and $\mu$. Therefore. $\beta_{\mu E_{-1}} \neq 0$ even if $\beta_{\mu E_{-1}^{*}}=0$. A similar arguement applies to $\beta_{v E}$. ( See Bound and Krueger (1991))

${ }^{8}$ We also show that the results in Bound et al. (2001) are special cases of this general expression. 
mean reversion is likely to be similar in both years. As a result, mean reversion is unlikely to have a large effect on estimates of $\beta$.

The second term in braces in equation 9 offers a somewhat more subtle source of bias in estimates of $\beta$. Following the previous literature we have not distinguished between two conceptually different sources of variation in earnings, $E^{*}$, which can lead to mean reversion. Since $E^{*}=\beta E_{-1}^{*}+\varepsilon$, log earnings can vary either because of variation in $\beta E_{-1}^{*}$ or because of variation in $\varepsilon$. The second term in braces allows mean reversion in $v$ to be different depending on whether the variation in log earnings is a result of variation in $E_{-1}^{*}$ or because of variation in $\varepsilon$. Since $\varepsilon$ may reflect factors such as unanticipated shocks to earning, this may affect reporting error differently than variation in lagged earnings. If $\beta_{v \varepsilon}=\beta_{v E^{*}}$ then the second term in braces is zero and, as a result, does not contribute to bias estimates of $\beta$.

Finally, the last term in braces shows that the standard attenuation bias, captured by $-\beta \frac{\operatorname{var}(\mu)}{\operatorname{var}\left(E_{-1}\right)}$, may be partially offset by positive covariance between $v$ and $\mu$ or between $\varepsilon$ and $\mu$. The former would happen if measurement error in earnings and lagged earnings were positively correlated $\left(\beta_{v \mu}>0\right)$. In terms of our application to earnings mobility, people who overstate their earnings in one period may tend to overstate their earnings in the other period. If $\beta_{v \mu}+\beta_{\varepsilon \mu}-\beta=0$, then attenuation bias is fully offset by these two factors.

These results on the impact of non-classical measurement error on estimates of the intertemporal elasticity of earnings, $\hat{\beta}$, also apply to estimates of the correlation in earnings since $\hat{\rho}=\hat{\beta} \frac{\sigma_{E-1}}{\sigma_{E}}$. Thus, non-classical measurement error affects $\hat{\rho}$ through the standard deviations of $E$ and $E_{-1}$ as well as through $\hat{\beta}$. However it is only the ratio of standard deviations that matter. Thus, even if non-classical measurement error has a large impact on estimates of $\sigma_{E}$ and $\sigma_{E_{-1}}$ this may have little effect on their ratio.

In summary, we have shown the analytical links between different forms of non-classical measurement error and estimates of $\beta$ and $\rho$. While the direction of the bias in $\hat{\beta}$ introduced by relaxing the classical assumptions depends on the sign and magnitudes of $\beta_{v E^{*}}, \beta_{\mu E_{-1}^{*}}$, $\beta_{v \mu}, \beta_{v \varepsilon}$ and $\beta_{\varepsilon \mu}$, we have shown the conditions under which these biases are offsetting.

\subsubsection{Classical measurement error}

It is useful to contrast these general results with the special case where $\mu$ and $v$ are classical random measurement error so $\beta_{v E^{*}}=\beta_{\mu E_{-1}^{*}}=\beta_{v \mu}=\beta_{v \varepsilon}=\beta_{\varepsilon \mu}=0$. Assuming that measurement error is not mean reverting $\left(\beta_{v E^{*}}=\beta_{\mu E_{-1}^{*}}=0\right)$ implies that measured inequality unambiguously leads to an overstatement of inequality since equation 5 shows that $\sigma_{E}^{2}-\sigma_{E^{*}}^{2}>0$. Measurement error affects the trend in inequality only if the variance of measurement error changes over time. Since mean reversion is assumed away it cannot affect the trend in inequality.

Classical measurement error also leads to an overestimate of mobility as measured by $\hat{\beta}$. Equation 9 simplifies to

$$
\hat{\beta}=\beta\left(1-\frac{\sigma^{2}(\mu)}{\sigma^{2}\left(E_{-1}\right)}\right)
$$

which reduces to the standard result

$$
\hat{\beta}=\beta \frac{\sigma^{2}\left(E_{-1}^{*}\right)}{\sigma^{2}\left(E_{-1}\right)}<\beta
$$


since $\operatorname{var}\left(E_{-1}\right)>\operatorname{var}\left(E_{-1}^{*}\right)$.

Classical measurement error also leads to an overestimate of mobility as measured by the correlation in earnings since ${ }^{9}$

$$
\hat{\rho}=\rho \frac{\sigma\left(E_{-1}^{*}\right) \sigma\left(E^{*}\right)}{\sigma\left(E_{-1}\right) \sigma(E)}<\rho
$$

Classical measurement error, therefore, increases mobility as well as inequality.

In summary we have shown that non-classical measurement error can lead to potentially offsetting effects on measures of inequality and mobility. In the following sections we provide estimates of the quantitative size of each of these effects and their net impact on estimates of inequality and mobility

\section{Empirical Results}

We apply these general results to measures of inequality and mobility estimated from reported earnings in the Survey of Income and Program Participation (SIPP) and from tax records in the Detailed Earnings Record (DER). While almost all of the literature implicitly assumes that administrative records provide "true" earnings, we do not take a stand on this issue since "true" earnings may depend on the question being asked. ${ }^{10}$

The question we ask is whether measures of inequality and mobility from the publicly available SIPP are unbiased estimates of inequality and mobility that would be obtained from confidential tax records. In terms of our previous notation , $E$ is log earnings as reported in $\mathrm{SIPP}, E^{*}$ is log earnings from tax records in the DER, and $\mu$ and $v$ are the differences in log earnings and lagged log earnings between these two data sets.

\subsection{Data}

We use data from the 1996 panel of the Survey of Income and Program Participation which are matched to the Detail Earnings Record at the Social Security Administration. ${ }^{11}$ SIPP respondents were interviewed in waves four months apart. At each wave they were asked to report their earnings for the previous four months, with detailed information on

$$
\begin{aligned}
\hat{\rho} & =\hat{\beta} \frac{\sigma\left(E_{-1}\right)}{\sigma(E)}=\beta \frac{\sigma\left(E_{-1}^{*}\right)}{\sigma\left(E_{-1}\right)} \frac{\sigma\left(E_{-1}\right)}{\sigma(E)} \\
& =\beta \frac{\sigma^{2}\left(E_{-1}^{*}\right)}{\sigma^{2}\left(E_{-1}\right)} \frac{\sigma\left(E_{-1}\right)}{\sigma(E)}=\beta \frac{\sigma^{2}\left(E_{-1}^{*}\right)}{\sigma\left(E_{-1}\right) \sigma(E)} \\
& =\left(\beta \frac{\sigma\left(E_{-1}^{*}\right)}{\sigma\left(E^{*}\right)}\right) \frac{\sigma\left(E_{-1}^{*}\right) \sigma\left(E^{*}\right)}{\sigma\left(E_{-1}\right) \sigma(E)}=\rho \frac{\sigma\left(E_{-1}^{*}\right) \sigma\left(E^{*}\right)}{\sigma\left(E_{-1}\right) \sigma(E)}
\end{aligned}
$$

${ }^{10}$ Abowd and Stinson (2004) consider the case where "true" earnings is not observed and both reported earnings and earnings from administrative data .are measured with error.

${ }^{11}$ Similar analysis were conducted on the 1984, 1990 and 1993 panels to assess changes in measurement error across time. These earlier panels show very similar results. 
up to two jobs. We restrict our sample to respondents with valid SIPP earnings in all 12 months of the calendar year (including zero earnings). ${ }^{12}$

We compare these measures of annual earnings from the SIPP with the counterpart constructed from the Detailed Earnings Records files that contain earnings information from W-2 forms for all jobs held by the respondent. ${ }^{13}$ The DER does not suffer from the standard limitations of FICA tax records which are top-coded at the FICA max and exclude jobs in sectors not covered by the FICA tax, such as state and local government workers.

The data in the DER are matched to SIPP respondents on the basis of their self-reported Social Security numbers. Respondents who fail to give their Social Security numbers or give invalid Social Security numbers cannot be matched and are, therefore, dropped. The match rates for our analysis sample is 77 percent.

SIPP earnings may differ from DER earnings for several reasons in addition to recall error. SIPP respondents are only asked to report earnings on up to two jobs in any month. If the respondent held more than two jobs, either simultaneously or sequentially, then the earnings in the additional jobs are missed in the SIPP but not in the DER.

In order to construct comparable DER earnings we exclude self-employment earnings and deferred earnings. The DER also differs from the SIPP since SIPP earnings are top-coded at $\$ 150,000$ per year and replaced by the mean earnings of persons classified by demographic characteristics. ${ }^{14}$ We, therefore, impose a similar procedure to the DER. ${ }^{15}$ In each year, we replace values above $\$ 150,000$ with the mean of earnings of persons with earnings above this threshold disaggregated by gender, ethnicity, race, match status - a total of 24 categories in each year.

Our analysis sample includes males, 25 to 62 , not attending school with positive yearly earnings. We also impose the sample restriction that respondents must have valid earnings in $t$ and $t-1$ in order to insure that variances and covariances come from the same sample. This restriction insures that the key identity in equation 9, holds exactly. Relaxing this restriction does not alter our conclusions.

\subsection{Summary Statistics}

Table 1 presents descriptive statistics for our analysis sample. Since roughly thirty percent of yearly earnings include at least one month of imputed earnings, and since imputations introduce an additional source of measurement error that can be avoided by dropping imputed earnings, we show all our results for the full sample and the sub-sample of observations with no monthly imputed values. Our full sample includes 3,742 yearly observations, of which 2,587 have all 12 months of non- imputed earnings. ${ }^{16}$

\footnotetext{
${ }^{12}$ Partial years in each panel are dropped since we require full year records to be comparable to the DER. The 996 panel has full year records for 1996 through 1999.

${ }^{13}$ DER records are available starting in 1978.

${ }^{14} \mathrm{SIPP}$ top coding is also based on monthly earnings and earnings within each wave which is not available in the DER.

${ }^{15}$ Note that this top coding procedure may be affected by measurement error since SIPP is top-coded on the basis of possibly mismeasured earnings.

${ }^{16} \mathrm{~A}$ yearly earnings observation is classified as non-imputed if none of the monthly observations are imputed.
} 
The demographic and employment characteristics of the full sample and the sub-sample are shown in columns 1 and 2. The average age in both columns is just above 41 and both columns show similar levels of education. Only race and ethnicity are substantially different across columns. Blacks are under-represented and Hispanics are over-represented in the sample that includes only non-imputed earnings. Employment characteristics are, however, similar with both the full sample and the subsample being largely composed of full-time, year-round workers

\subsection{Means and Variances}

Table 2 presents means and variances of log earnings in the DER and SIPP, as well as the mean and variance of measurement error. ${ }^{17}$ These summary statistics indicate that measurement error is large in the SIPP. Mean log earnings are understated by .15 for the full sample and by .12 for the sample that includes only non-imputed earnings. One possible reason for this large mean discrepancy is that the SIPP includes only information on two jobs.

Not only does SIPP provide an underestimate of mean earnings in the DER, the variance in measurement error is also large. The signal to noise ratio, as measured by $\frac{\operatorname{var}(D E R)}{\operatorname{var}(\text { error })}$, is roughly 2.0 when cases with imputed earnings are included. This signal to noise ratio increases only to 2.6 when imputed earnings are excluded.

For comparison with other studies, we also show what is known in the literature as the reliability ratio for classical measurement error, $\frac{\operatorname{var}(D E R)}{\operatorname{var}(D E R)+\operatorname{var}(\text { error })}$. The reliability ratio, is .67 for the full sample and .73 for cases with non-imputed earnings. This is consistent with the value of .7 reported for the PSID in Bound et al. (1994) and for values around .8 reported for the CPS in Bound and Krueger (1991). ${ }^{18}$

If measurement error were classical then the large variance in measurement error would lead to substantially greater measures of inequality in the SIPP than in the DER. However, Table 2 shows the opposite. The variance of log earnings in DER earnings of .68 is somewhat larger than the variance in SIPP earnings for all respondents of .56 , or the value for respondents with non-imputed earnings of .53.

Table 3 shows that SIPP estimates of the mean and variance of log earnings are not only lower than DER estimates for the whole sample but that these patterns hold for persons disaggregated demographic characteristics. Columns 1 to 5 show that all demographic groups have lower mean earnings in the SIPP than the DER . Furthermore, the differences in means across data sets are of similar magnitude for the different demographic groups. As a result, mean differences in earnings across demographic groups that are statistically significant in the DER continue to be significant in the SIPP. ${ }^{19}$

Columns 6 to 10 display the variances of log earnings in the DER and the SIPP for

\footnotetext{
${ }^{17}$ Since our analysis sample includes only respondents who could be matched in the two data sets, Table A1 in the appendix also shows the mean and variance in the DER before this cut is imposed. This table shows that the imposing this cut yields an analysis sample with somewhat higher mean and lower variance of log earnings.

${ }^{18}$ See Table 1 of Bound et al. (1994) and Table 6 of Bound and Krueger (1991)

${ }^{19}$ This conclusion is based on the coefficients of a mean regression with a full set of demographic characteristics.
} 
these demographic groups. Again the general patterns hold within demographic groups since the variance is lower in the SIPP than the DER for all groups except non-Hispanics. Furthermore, the magnitude of the differences are similar across demographic groups, which leaves group differences in inequality largely unaffected.

In summary, the SIPP yields lower estimates of the variance of log earnings than the DER, even within demographic cells. As we have shown, this is the result of measurement error being mean reverting. This mean reversion more than offsets the additional variance of measurement error in reported earnings. In terms of our previous notation the variance in SIPP understates the variance in the DER because $\left|\sigma_{E^{*} v}\right|>.5 \sigma_{v}^{2}$.

\subsection{Elasticities and Correlations}

Table 4 shows estimates of the intertemporal elasticity of earnings, $\beta$, and and correlation of log earnings, $\rho$. Row 1 shows estimates based on the DER. The estimated elasticity of .868 indicates is slightly higher than the .845 elasticity for the SIPP sample and nearly identical to the .867 elasticity for the SIPP sample that includes only non-imputed earnings. Likewise the correlations are similar in the two data sets. The DER yields a correlation of .834 while the SIPP yields estimates of .831 and .865, depending on whether or not imputed earnings are included. ${ }^{20}$

Table 5 presents estimates of these mobility measures for the same demographic groups shown in Table 3. Again the results for the full sample are largely replicated within demographic groups. Comparing estimates of $\hat{\beta}$ and $\hat{\rho}$ across data sets shows small differences. especially when compared with differences across demographic groups. For example, the intertemporal elasticities of earnings for Blacks is .874 in the DER and .850 in the SIPP. This -.024 difference across data sets is small compared to the .121 difference between Blacks and non-Blacks in both data sets.

We conclude that demographic specific estimates of $\beta$ and $\rho$ are similar across data sets and that the differences are sufficiently small that conclusions about differences in mobility across groups based on SIPP mobility measures are generally similar to conclusions based on the DER. While the SIPP and DER estimates are remarkably similar, this does not mean that measurement error is not large. In fact the large variance of measurement error shown in Table 2 for the full sample is also found within demographic groups. This would lead to large attenuation bias if measurement error were classical. The fact that mobility measures in the SIPP are similar to those in the DER implies that the non-classical nature of measurement error largely offsets the attenuation bias.

\subsection{Structure of Measurement Error}

Table 6 presents the non-classical structure of measurement error by displaying estimates of the key parameters in equation 9 . The first row verifies that measurement error is indeed mean reverting, as implied by the findings in Tables 2 and 3 that the variance of log earnings is smaller in SIPP than in DER . Our point estimate of -.339 for $\beta_{v E^{*}}$ and -.292 for $\beta_{\mu E_{-1}^{*}}$ are significantly less than zero.

\footnotetext{
${ }^{20}$ The measure of immobility developed in Shorrocks (1978), which is also based on second moments of log earnings, is also very similar in the two data sets ( .922 for the DER and .908 for the SIPP.)
} 
While mean reversion lowers the variance of earnings, the first term in braces in equation $9,\left\{\left(\beta_{v E^{*}}-\beta_{\mu E_{-1}^{*}}\right) \frac{\operatorname{var}\left(E_{-1}^{*}\right)}{\operatorname{var}\left(E_{-1}\right)}\right\}$, shows that it is only the difference between $\beta_{v E^{*}}$ and $\beta_{\mu E_{-1}^{*}}$ that affects estimates of the intertemporal elasticity of earnings, $\hat{\beta}$. Since the difference between the point estimates of -.339 and -.292 is small, mean reversion has only a small impact on SIPP estimates of mobility.

The second term in braces in equation $9,\left\{\left(\beta_{v E^{*}}-\beta_{v \varepsilon}\right) \frac{\operatorname{var}(\varepsilon)}{\beta v a r\left(E_{-1}\right)}\right\}$, shows that SIPP estimates of the the intertemporal elasticity of earnings depend on whether deviations from expected earnings, $\varepsilon$, are reported with the same degree of mean reversion as actual earnings, $E^{*}{ }^{21}$ Table 6 shows that a one percent increase in deviation. from expected earnings, $\varepsilon$, is accompanied by an offsetting .550 percent reduction in measurement error. This is substantially larger than the .339 percent reduction in measurement error from a one percent change in actual earnings, $E^{*}$. This implies that respondents tend to understate their earnings even more when their earnings reflect transitory deviations from expected earnings. This under-reporting of deviations from expected earnings increases the correlation in reported earnings across time and, hence, leads to higher estimates of $\hat{\beta}$ in the SIPP than the DER.

Finally, the sign of the third term in braces in equation $9,\left\{\left[\beta_{v \mu}+\beta_{\varepsilon \mu}-\beta\right] \frac{\operatorname{var}(\mu)}{\operatorname{var}\left(E_{-1}\right)}\right\}$, depends on whether two additional sources of non-classical measurement, $\beta_{v \mu}$ and $\beta_{\varepsilon \mu}$, are sufficiently strong to offset the standard source of attentuation bias, given by $-\beta \frac{\operatorname{var}(\mu)}{\operatorname{var}\left(E_{-1}\right)}$. The first of these potentially offsetting effects, $\beta_{v \mu}$, allows measurement error in earnings and lagged earnings to be correlated. If measurement errors are positively correlated then this itself will raise SIPP estimates of $\hat{\beta}$. This serves to offset the negative impact of attenuation bias. Our estimate of $\beta_{v \mu}$ indicates that a one percent increase in measurement error in lagged earnings is associated with a .540 percent increase in measurement error in earnings. This positive correlation in measurement error results in positive correlation in reported earnings, which offsets the attenuation bias of classical measurement error.

The second potentially offsetting effect of non-classical measurement error, $\beta_{\varepsilon \mu}$, allows measurement error in lagged earnings, $\mu$, to be correlated with deviations from expected earnings, $\varepsilon$. For example, respondents experiencing transitorily high earnings in period $t$ may extrapolate these high earnings back to period $t-1$. Since earnings in $t-1$ are reported in period $t$, this would result in measurement error in reported prior earnings being correlated with current transitory earnings. The positive and significant point estimate of .198 for $\beta_{\varepsilon \mu}$ in the bottom row of Table 6 is consistent with this behavior. Since estimates of both $\beta_{v \mu}$ and $\beta_{\varepsilon \mu}$ are positive these sources of non-classical measurement error offset the attentuation bias of classical measurement error.

In summary, non-classical measurement error introduces a set of factors that offset the attentuation bias of classical measurement error. The only source of non-classical measurement error that reinforces classical attenuation bias is mean reversion. And since it is only the difference in mean reversion of measurement error in earnings and lagged earnings that matters, its impact is likely to be small.

\footnotetext{
${ }^{21}$ Recall that $E^{*}$ includes the effects of $\beta E_{-1}^{*}$ as well as $\varepsilon$.
} 


\subsection{Impact of Separate Components}

In order to assess the importance of the individual components of measurement error described in the previous section, we use equations 5 and 9 to calculate the variance of log earnings, $\hat{\sigma}^{2}$, and our two measures of mobility, $\hat{\beta}$ and $\hat{\rho}$, under a set of counterfactual assumptions. The top panel of Table 7 replicates the estimated values of $\hat{\sigma}^{2}, \hat{\beta}$ and $\hat{\rho}$ from the DER and SIPP shown in Tables 2 and 4. These are shown for comparison with the counterfactual values in the bottom panel. The four rows in the bottom panel show the values under the following counterfactual assumptions.

Row 3 shows the values of $\hat{\sigma}^{2}, \hat{\beta}$ and $\hat{\rho}$ under the counterfactual assumption that all measurement error in SIPP is classical by setting $\beta_{v E^{*}}, \beta_{\mu E_{-1}^{*}}, \beta_{\varepsilon \mu}$ and $\beta_{v \mu}$ in equations 5 and 9 all equal to zero. Given the large measurement error shown in Table 2, this would naturally lead to a high variance of log earnings since the random measurement error would add to the variance of log earnings. Similarly random measurement error would lead to spurious mobility. This would lead to low values of $\hat{\beta}$ and $\hat{\rho}$. Row 3 shows that if all measurement error were classical, the variance of log earnings in the SIPP would be roughly 1.5 times larger than the variance of log earnings in the DER (1.027 versus .684). Similarly, if measurement error were classical, both $\hat{\beta}$ and $\hat{\rho}$ would be less than half as large in the SIPP as in the DER.

Row 4 relaxes the classical assumptions that $\beta_{v \mu}$ and $\beta_{\varepsilon \mu}$ are both zero, and that the third bracketed term in equation 9 is, therefore, also zero. Allowing $\left[\beta_{v \mu}+\beta_{\varepsilon \mu}\right]$ to take on the positive value based on the values of $\beta_{v \mu}$ and $\beta_{\varepsilon \mu}$ in Table 6 allows measurement error in earnings and lagged earnings to be positively correlated and allows measurement error in lagged earnings to be positively correlated with deviations from expected earnings. These sources of non-classical measurement error have a large impact on $\hat{\beta}$ and $\hat{\rho}$. Under this counterfactual, the SIPP estimate of the elasticity increases to .813, which brings it much closer to the DER value of .868. Similarly the SIPP value for $\hat{\rho}$ would be .766, which makes up much of the gap with the DER value of .834. Thus, allowing $\beta_{v \mu}$ and $\beta_{\varepsilon \mu}$ to be non-zero largely offsets the attenuation bias of classical measurement error. This gap closing effect of non-classical measurement error is primarily the result of allowing for correlation in measurement error in earnings and in lagged earnings since $\beta_{v \mu}$ is more than twice as large as $\beta_{\varepsilon \mu}$

Row 5 further relaxes the classical assumption that the second term in braces in equation 9 is zero by also letting $\left(\beta_{v E^{*}}-\beta_{v \varepsilon}\right)$ take its value of .211 in Table $6 .{ }^{22}$ Since this term is positive, its effect is to further raise $\beta$ from .813 to .892 and to raise $\hat{\rho}$ from.766 to .840 These counterfactual values of $\hat{\beta}$ and $\hat{\rho}$ are somewhat above the values shown in the top panel.

Finally Row 6 of the bottom panel also allows for mean reversion by allowing $\left(\beta_{v E^{*}}-\right.$ $\left.\beta_{\mu E_{-1}^{*}}\right)$ to take its value of -.047 in Table $6 .{ }^{23}$ Since $\left(\beta_{v E^{*}}-\beta_{\mu E_{-1}^{*}}\right)$ is negative and since this term determines the sign of the first term in braces in equation 9 , relaxing the classical assumption of no-mean reversion leads to lower values of $\hat{\beta}$ and $\hat{\rho}$. But the effect is small.

Since the impact of mean reversion on the variance of the marginal distribution of earnings, $\hat{\sigma}^{2}$, depends on $\beta_{v E^{*}}$, rather than on the difference between $\beta_{v E^{*}}$ and $\beta_{\mu E_{-1}^{*}}$, the impact of mean reversion on inequality is substantially larger than its impact on mobility. Allowing

\footnotetext{
${ }^{22}\left(\beta_{v E^{*}}-\beta_{v \varepsilon}\right)=.550-.339=.211$.

${ }^{23}$ Since equation 9 holds exactly and since all the relevant classical assumptions have been relaxed, we arrive back at the SIPP values in the top panel.
} 
for mean reversion cuts the value of $\hat{\sigma}^{2}$ nearly in half, from 1.027 to .563 .

In summary, classical measurement error would have led to substantially higher values of $\hat{\sigma}^{2}$ and to lower values $\hat{\beta}$ and $\hat{\rho}$ in the SIPP than in the DER. The fact that the SIPP shows lower values of $\hat{\sigma}^{2}$ than the DER reflects the strong mean reversion in measurement error which more than offsets the inequality increasing effect of the large variance of measurement error. The fact that the SIPP and DER give very similar values for the intertemporal elasticity of earnings and for the correlation in earnings is largely the result of another source of non-classical measurement error. While classical measurement error assumes that errors in reported earnings and lagged earnings are independent we find strong correlation in these two sources of measurement error. These correlated errors largely offset the attenuation bias of classical measurement error. As a result estimates of the intertemporal elasticity and correlation in log earnings are very similar in these two data sets.

\section{Conclusion}

We have presented a general framework that can be used to analyze the impact of nonclassical measurement on measures of inequality and mobility. While classical measurement error leads to upward bias in both inequality and mobility, non-classical measurement error introduces a set of potentially important offsetting factors. For example, mean reverting measurement error can lead to downward bias in estimates of inequality which offsets the increased variance from classical measurement error. Likewise, correlated measurement error can fully offset the attenuation bias in estimates of the correlation in earnings.

Our empirical application shows that there is substantial measurement error in SIPP earnings This measurement error is, however, far from classical. Measurement error is not only correlated with log earnings but measurement error is also strongly positively correlated across time.

The net impact of non-classical measurement error is that inequality is underestimated in SIPP. Mobility is, however, affected much less than inequality by measurement error. This is the result of large but offsetting biases in measures of earnings and lagged earnings

\section{A Appendix A-Nonlinearities}

The analytical and empirical work in this paper examines the linear relationships between log earnings, lagged log earnings and various aspects of measurement error. For example, we have followed the literature by examining the linear correlation between log earnings, lagged log earnings and the linear relationship between measurement error, lagged measurement error and various aspects of log earnings.

This Appendix examines whether these and other relationships are linear by plotting conditional expectations without imposing linearity. We divide the conditioning variable into 100 bins based on percentiles and plot the conditional mean of the variable (within each bin) on the vertical axis. ${ }^{24}$

\footnotetext{
${ }^{24} \mathrm{~A}$ computational intensive alternative would be to kernal smooth the ungroupded data. This is not done because the number of observations to be smoothed is very large.
} 
Figure 1 plots the conditional mean of log earnings in the SIPP for each percentile of log earnings in the DER. These conditional means of reported log earnings show that measurement error models based on log linear relationships are consistent with the data,

Figure 2 plots mean DER log earnings, conditional on lagged DER log earnings. Figure 3 presents the same conditional means for SIPP log earnings. Both plots show a strong linear relationship in logs. This implies that the linear correlation between log earnings and lagged log earnings used throughout the mobility literature captures the key features of the data.

Figures 4 and 5 show that the linear properties of measurement error assumed in this literature are largely preserved in these non-parametric plots. Figure 4 plots mean measurement error against DER log earnings. This graph shows strong mean reversion in the lower third of the distribution of log earnings. There is also mean reversion higher in the distribution but it is weaker. ${ }^{25}$ However, Figure 5 shows a strong positive linear relationship between mean measurement error and lagged measurement error throughout the distribution.

These plots show that implicit assumption of linearity in much of the literature on log additive measurement error is consistent with data. The only qualification is that mean reversion is stronger at low levels of earnings.

\section{B Appendix B-Derivations}

In this appendix we show how equation 9 is derived from equation 8 . We then show that results in Bound et al. (2001) are special cases of equation 9.

\section{B.1 Derivation of Equation 9}

To derive equation 9 start with equation 8

$$
\hat{\beta}=\beta\left(1-\beta_{\mu E_{-1}}\right)+\beta_{v E_{-1}}+\beta_{\varepsilon \mu} \frac{\operatorname{var}(\mu)}{\operatorname{var}\left(E_{-1}\right)}
$$

$\beta_{\mu E_{-1}^{*}}$ is introduced by recognizing that

$$
\begin{aligned}
\beta_{\mu E_{-1}} & =\frac{\operatorname{cov}\left(\mu, E_{-1}^{*}+\mu\right)}{\operatorname{var}\left(E_{-1}\right)} \\
& =\beta_{\mu E_{-1}^{*}} \frac{\operatorname{var}\left(E_{-1}^{*}\right)}{\operatorname{var}\left(E_{-1}\right)}+\frac{\operatorname{var}(\mu)}{\operatorname{var}\left(E_{-1}\right)}
\end{aligned}
$$

. Therefore,

$$
\hat{\beta}=\beta\left(1-\beta_{\mu E_{-1}^{*}} \frac{\operatorname{var}\left(E_{-1}^{*}\right)}{\operatorname{var}\left(E_{-1}\right)}-\frac{\operatorname{var}(\mu)}{\operatorname{var}\left(E_{-1}\right)}\right)+\beta_{v E_{-1}}+\beta_{\varepsilon \mu} \frac{\operatorname{var}(\mu)}{\operatorname{var}\left(E_{-1}\right)}
$$

\footnotetext{
${ }^{25}$ This is consistent with the findings for the CPS reported in Bound and Krueger (1991).
} 
$\beta_{v E^{*}}$ is introduced by recognizing that $\beta_{v E_{-1}}$ can be written in terms of $\beta_{v E^{*}}$ and $\beta_{v \mu}$ :

$$
\begin{aligned}
\beta_{v E_{-1}} & =\frac{\operatorname{cov}\left(v E_{-1}\right)}{\operatorname{var}\left(E_{-1}\right)}=\frac{\operatorname{cov}\left(v, E_{-1}^{*}+\mu\right)}{\operatorname{var}\left(E_{-1}\right)} \\
& =\frac{\operatorname{cov}\left(v, \frac{E^{*}}{\beta}-\frac{\varepsilon}{\beta}+\mu\right)}{\operatorname{var}(x)} \\
& =\frac{\operatorname{cov}\left(v, E^{*}\right)-\operatorname{cov}(v \varepsilon)+\beta \operatorname{cov}(v, \mu)}{\beta \operatorname{var}\left(E_{-1}\right)} \\
& =\frac{\beta_{v E^{*}} \frac{\operatorname{var}\left(E^{*}\right)}{\beta}-\frac{\beta_{v \varepsilon}}{\operatorname{var}\left(E_{-1}\right)}}{\operatorname{var}(\varepsilon)}+\beta_{v \mu} \frac{\operatorname{var}(\mu)}{\operatorname{var}\left(E_{-1}\right)}
\end{aligned}
$$

Substituting 20 into 19:

$$
\begin{aligned}
\hat{\beta}= & \beta\left(1-\beta_{\mu E_{-1}^{*}} \frac{\operatorname{var}\left(E_{-1}^{*}\right)}{\operatorname{var}\left(E_{-1}\right)}-\frac{\operatorname{var}(\mu)}{\operatorname{var}\left(E_{-1}\right)}\right)+\frac{\beta_{v E^{*}} \frac{\operatorname{var}\left(y^{*}\right)}{\beta}}{\operatorname{var}\left(E_{-1}\right)} \\
& -\frac{\beta_{v \varepsilon}}{\beta} \frac{\operatorname{var}(\varepsilon)}{\operatorname{var}\left(E_{-1}\right)}+\beta_{v \mu} \frac{\operatorname{var}(\mu)}{\operatorname{var}\left(E_{-1}\right)}+\beta_{\varepsilon \mu} \frac{\operatorname{var}(\mu)}{\operatorname{var}\left(E_{-1}\right)} \\
= & \beta\left(1-\beta_{\mu E_{-1}^{*}} \frac{\operatorname{var}\left(E_{-1}^{*}\right)}{\operatorname{var}\left(E_{-1}\right)}\right)+\frac{\beta_{v E^{*}}}{\beta} \frac{\operatorname{var}\left(E^{*}\right)}{\operatorname{var}\left(E_{-1}\right)}-\frac{\beta_{v \varepsilon}}{\beta} \frac{\operatorname{var}(\varepsilon)}{\operatorname{var}\left(E_{-1}\right)} \\
& +\left[\beta_{v \mu}+\beta_{\varepsilon \mu}-\beta\right] \frac{\operatorname{var}(\mu)}{\operatorname{var}\left(E_{-1}\right)} \\
= & \beta\left(1-\beta_{\mu E_{-1}^{*}} \frac{\operatorname{var}\left(E_{-1}^{*}\right)}{\operatorname{var}\left(E_{-1}\right)}\right)+\frac{\beta_{v y^{*}}}{\beta} \frac{\operatorname{var}\left(E^{*}\right)}{\operatorname{var}\left(E_{-1}\right)}-\frac{\beta_{v \varepsilon}}{\beta} \frac{\operatorname{var}(\varepsilon)}{\operatorname{var}\left(E_{-1}\right)} \\
& +\left[\beta_{v \mu}+\beta_{\varepsilon \mu}-\beta\right] \frac{\operatorname{var}(\mu)}{\operatorname{var}\left(E_{-1}\right)}
\end{aligned}
$$

This expression can be simplified by recognizing that $\operatorname{var}\left(E^{*}\right)=\beta^{2} \operatorname{var}\left(E_{-1}^{*}\right)+\operatorname{var}(\varepsilon)$. Substituting this into 21 yields:

$$
\begin{aligned}
\hat{\beta}= & \beta\left(1-\beta_{\mu E_{-1}^{*}} \frac{\operatorname{var}\left(E_{-1}^{*}\right)}{\operatorname{var}\left(E_{-1}\right)}\right)+\frac{\beta_{v e^{*}}}{\beta} \frac{\beta^{2} \operatorname{var}\left(E_{-1}^{*}\right)+\operatorname{var}(\varepsilon)}{\operatorname{var}\left(E_{-1}\right)} \\
& -\frac{\beta_{v \varepsilon}}{\beta} \frac{\operatorname{var}(\varepsilon)}{\operatorname{var}\left(E_{-1}\right)}+\left[\beta_{v \mu}+\beta_{\varepsilon \mu}-\beta\right] \frac{\operatorname{var}(\mu)}{\operatorname{var}\left(E_{-1}\right)} \\
= & \beta\left(1-\beta_{\mu E_{-1}^{*}} \frac{\operatorname{var}\left(E_{-1}^{*}\right)}{\operatorname{var}\left(E_{-1}\right)}\right)+\beta \beta_{v E^{*}} \frac{\operatorname{var}\left(E_{-1}^{*}\right)}{\operatorname{var}\left(E_{-1}\right)}+\frac{\beta_{v E^{*}}}{\beta} \frac{\operatorname{var}(\varepsilon)}{\operatorname{var}\left(E_{-1}\right)} \\
& -\frac{\beta_{v \varepsilon}}{\beta} \frac{\operatorname{var}(\varepsilon)}{\operatorname{var}\left(E_{-1}\right)}+\left[\beta_{v \mu}+\beta_{\varepsilon \mu}-\beta\right] \frac{\operatorname{var}(\mu)}{\operatorname{var}\left(E_{-1}\right)} \\
= & \beta\left(1+\left\{\left(\beta_{v E^{*}}-\beta_{\mu E_{-1}^{*}}\right) \frac{\operatorname{var}\left(E_{-1}^{*}\right)}{\operatorname{var}\left(E_{-1}\right)}\right\}\right) \\
& +\left\{\left(\beta_{v E^{*}}-\beta_{v \varepsilon}\right) \frac{\operatorname{var}(\varepsilon)}{\beta \operatorname{var}\left(E_{-1}\right)}\right\}+\left\{\left[\beta_{v \mu}+\beta_{\varepsilon \mu}-\beta\right] \frac{\operatorname{var}(\mu)}{\operatorname{var}\left(E_{-1}\right)}\right\}
\end{aligned}
$$

which is equation 9. This gives $\hat{\beta}$ in terms of $\beta_{v E^{*}}, \beta_{\mu E_{-1}^{*}}, \beta_{v \mu}, \beta_{v \varepsilon}$ and $\beta_{\varepsilon \mu}$ the five parameters that capture the non-classical nature of the measurement error. 


\section{B.2 Generalization of Bound et al. (2001)}

Bound et al. (2001) considers measurement error in either $E$ or $E_{-1}$, . but not both. Since there is only one source of measurement error $\beta_{v \mu}=0$. Bound et al. (2001) further assumes that $\beta_{\varepsilon \mu}=\beta_{v \varepsilon}=0$. Equation 9, therefore simplifies to

$$
\hat{\beta}=\beta\left(1-\beta_{\mu E_{-1}}\right)+\beta_{v E_{-1}}
$$

Likewise equation 20 simplifies to

$$
\beta_{v E_{-1}}=\frac{\beta_{v E^{*}}}{\beta} \frac{\operatorname{var}\left(E^{*}\right)}{\operatorname{var}\left(E_{-1}\right)}
$$

and equation 9 reduces to

$$
\hat{\beta}=\beta\left(1+\left(\beta_{v E^{*}}-\beta_{\mu E_{-1}^{*}}\right) \frac{\operatorname{var}\left(E_{-1}^{*}\right)}{\operatorname{var}\left(E_{-1}\right)}\right)+\beta_{v y^{*}} \frac{\operatorname{var}(\varepsilon)}{\beta \operatorname{var}\left(E_{-1}\right)}-\beta \frac{\operatorname{var}(\mu)}{\operatorname{var}\left(E_{-1}\right)}
$$

If there is only measurement error in $E_{-1}$ and this measurement error is allowed to depend on $E_{-1}^{*}$ but is assumed to be independent of $E^{*}$ (and independent of $\varepsilon$ ) then equation 25 simplifies to

$$
\begin{aligned}
\hat{\beta} & \left.=\beta\left(1-\beta_{\mu E_{-1}^{*}}\right) \frac{\operatorname{var}\left(E_{-1}^{*}\right)}{\operatorname{var}\left(E_{-1}\right)}\right)-\beta \frac{\operatorname{var}(\mu)}{\operatorname{var}\left(E_{-1}\right)} \\
& =\beta\left(1-\beta_{\mu E_{-1}}\right)
\end{aligned}
$$

which matches Bound et al. (2001) page 3713 .

While Bound et al. (2001) does not present an explicit expression for the impact of non-classical measurement error in $E$ they conclude that mean reverting measurement error leads to downward bias in estimates of $\beta$. This conclusion is consistent with equation 25 . Let $\beta_{\mu E_{-1}^{*}}=0$. so

$$
\begin{aligned}
\hat{\beta} & =\beta\left(1+\beta_{v E^{*}} \frac{\operatorname{var}\left(E_{-1}^{*}\right)}{\operatorname{var}\left(E_{-1}\right)}\right)+\beta_{v y^{*}} \frac{\operatorname{var}(\varepsilon)}{\beta \operatorname{var}\left(E_{-1}\right)}-\beta \frac{\operatorname{var}(\mu)}{\operatorname{var}\left(E_{-1}\right)} \\
& =\beta\left(1+\beta_{v E^{*}}\left(\frac{\operatorname{var}\left(E_{-1}^{*}\right)}{\operatorname{var}\left(E_{-1}\right)}+\frac{\operatorname{var}(\varepsilon)}{\beta \operatorname{var}\left(E_{-1}\right)}\right)\right)-\beta \frac{\operatorname{var}(\mu)}{\operatorname{var}\left(E_{-1}\right)}
\end{aligned}
$$

Since $E_{-1}=E_{-1}^{*}$ then $\operatorname{var}\left(E_{-1}^{*}\right)=\operatorname{var}\left(E_{-1}\right)$ and $\operatorname{var}(\mu)=0$, so

$$
\hat{\beta}=\beta\left[1+\beta_{v E^{*}}\left(1+\frac{\operatorname{var}(\varepsilon)}{\beta \operatorname{var}\left(E_{-1}\right)}\right)\right]
$$

which is consistent with the conclusion in Bound et al. (2001) that mean reverting measurement error leads to downward bias. 


\section{References}

Abowd, J. M. and M. Stinson (2004). Estimating Measurement Error in SIPP Annual Job Earnings: A Comparison of Census Survey and SSA Administrative Data. http://instruct1.cit.cornell.edu/ jma7/abowd-stinson-SOLE-2003.pdf.

Bollinger, C. R. (1998). Measurement Error in the Current Population Survey: A Nonparametric Look. Journal of Labor Economics 16(3), 576-94.

Bound, J., C. Brown, G. L. Duncan, and W. L. Rodgers (1994, July). Evidence on the Validity of Cross-sectional and Longitudinal Labor Market Data. Journal of Labor Economics 12(2), 345-368.

Bound, J., C. Brown, and N. Mathiowitz (2001). Measurement Error in Survey Data. In J. J. Heckman and E. Leamer (Eds.), Handbook of Econometrics, Chapter 59, pp. 3707-3745. Amsterdam; London and New York: Elsevier Science B.V.

Bound, J. and A. B. Krueger (1991, January). The Extent of Measurement Error in Longitudinal Earnings Data: Do Two Wrongs Make a Right? Journal of Labor Economics 9(1), $1-24$.

Coder, J. and L. Scoon-Rogers (1996). Evaluating the Quality of Income Data Collected in the Annual Supplement to the March Current Population Survey and the Survey of Income and Program Participation. Household and Economic Statistics Division Working Paper Series. Bureau of the Census, Department of Commerce.

Dragoset, L. M. and G. S. Fields (2006, May). U.S. Earnings Mobility: Comparing SurveyBased and Administrative-Based Estimates. manuscript.

Duncan, G. J. and D. Hill (1985). An Investigation of the Extent and Consequences of Measurement Error in Labor-economic Survey Data. Journal of Labor Economics 3(4), $508-32$.

Fields, G. S. (2005, July). Does Income Mobility Equalize Longer-Term Incomes? New Measures of An Old Concept. Cornell University.

MaCurdy, T. E. (1982, January). The Use of Time Series Processes to Model the Error Structure of Earnings in a Longitudinal Data Analysis. Journal of Econometrics 18(1), 83-114.

Pischke, J. (1995). Measurement Error and Earnings Dynamics: Some Estimates From PSID Validation Study. Journal of Business and Economic Statistics 13(3), 305-14.

Shorrocks, A. (1978). Income Inequality and Income Mobility. Journal of Economic Theory $19(2), 376-393$. 
Table 1: Descriptive Statistics

\begin{tabular}{lcc} 
& All & Non-imputed \\
\cline { 2 - 3 } Black & 0.086 & 0.060 \\
Hispanic & 0.087 & 0.094 \\
Age & 41.6 & 41.3 \\
Education & & \\
$\quad<12$ & 0.084 & 0.087 \\
$\quad \mathbf{1 2 - 1 5}$ & 0.611 & 0.601 \\
$\mathbf{1 6 +}$ & 0.305 & 0.311 \\
& & \\
Hours & 2215 & 2231 \\
Week & 50.6 & 50.8 \\
Imputed earnings & 0.309 & 0.000 \\
& & \\
Obs & 3742 & 2587
\end{tabular}


Table 2: Mean and Variance of Log Earnings and Measurement Error

\begin{tabular}{lccc} 
& Mean & Variance & obs \\
\cline { 2 - 4 } Log earnings & & & \\
\hline DER & 10.53 & 0.68 & \\
SIPP & & & \\
All & 10.38 & 0.56 & 3742 \\
Non-imputed & 10.42 & 0.53 & 2587
\end{tabular}

Measurement Error

$\begin{array}{llll}\text { All } & -0.15 & 0.34 & 3742 \\ \text { Non-imputed } & -0.12 & 0.26 & 2587\end{array}$

\section{Signal to noise ratio}

$\begin{array}{ll}\text { All } & 1.99 \\ \text { Non-imputed } & 2.64\end{array}$

Realiability ratio
All
0.67
Non-imputed
0.73

Note:

(1) Signal to noise ratio=var(DER)/var(error)

(2) Reliability ratio=var(DER)/[var(DER)+var(error)] 
Table 3: Means and Variances by Demographic Groups
(1)
(2)
(3)
(4)
(5)
(6) (7)
(8)
(9)
(10)

\begin{tabular}{|c|c|c|c|c|c|c|c|c|c|c|}
\hline & & & & & & & & Varianc & & \\
\hline & DER & SIPP & (2)-(1) & SIPP NI & (4)-(1) & DER & SIPP & $(7)-(6)$ & SIPP NI & $(9)-(6)$ \\
\hline Black & 10.561 & 10.412 & -0.150 & 10.442 & -0.119 & 0.691 & 0.573 & -0.118 & 0.527 & -0.164 \\
\hline Non-Black & 10.224 & 10.095 & -0.129 & 10.033 & -0.191 & 0.506 & 0.361 & -0.145 & 0.448 & -0.058 \\
\hline Hispanic & 10.560 & 10.417 & -0.143 & 10.455 & -0.105 & 0.699 & 0.559 & -0.141 & 0.520 & -0.180 \\
\hline Non-Hispanic & 10.244 & 10.044 & -0.200 & 10.056 & -0.188 & 0.431 & 0.481 & 0.050 & 0.502 & 0.071 \\
\hline Ages & & & & & & & & & & \\
\hline 30 & 10.195 & 10.110 & -0.084 & 10.164 & -0.031 & 0.550 & 0.432 & -0.118 & 0.370 & -0.180 \\
\hline 35 & 10.433 & 10.340 & -0.093 & 10.387 & -0.046 & 0.709 & 0.434 & -0.275 & 0.429 & -0.279 \\
\hline 40 & 10.616 & 10.441 & -0.175 & 10.472 & -0.144 & 0.573 & 0.628 & 0.055 & 0.547 & -0.027 \\
\hline 45 & 10.622 & 10.453 & -0.169 & 10.484 & -0.138 & 0.621 & 0.574 & -0.047 & 0.612 & -0.008 \\
\hline 50 & 10.674 & 10.504 & -0.170 & 10.488 & -0.186 & 0.592 & 0.490 & -0.102 & 0.473 & -0.119 \\
\hline 55 & 10.608 & 10.426 & -0.182 & 10.517 & -0.091 & 0.951 & 0.604 & -0.347 & 0.585 & -0.365 \\
\hline 60 & 10.569 & 10.395 & -0.175 & 10.414 & -0.155 & 0.753 & 0.733 & -0.020 & 0.693 & -0.060 \\
\hline 65 & 10.330 & 10.191 & -0.139 & 10.075 & -0.256 & 0.860 & 0.886 & 0.026 & 0.633 & -0.228 \\
\hline det & & & & & & & & & & \\
\hline$<12$ & 9.982 & 9.809 & -0.173 & 9.818 & -0.163 & 0.684 & 0.593 & -0.091 & 0.584 & -0.100 \\
\hline 12 & 10.291 & 10.171 & -0.120 & 10.202 & -0.089 & 0.604 & 0.421 & -0.183 & 0.376 & -0.227 \\
\hline $12-15$ & 10.487 & 10.367 & -0.121 & 10.401 & -0.086 & 0.559 & 0.437 & -0.121 & 0.443 & -0.116 \\
\hline 16 & 10.887 & 10.686 & -0.201 & 10.714 & -0.173 & 0.433 & 0.432 & 0.000 & 0.390 & -0.042 \\
\hline$>16$ & 11.158 & 10.961 & -0.197 & 11.015 & -0.143 & 0.610 & 0.603 & -0.007 & 0.466 & -0.144 \\
\hline
\end{tabular}


Table 4: Elasticity and Correlation

\begin{tabular}{lcc} 
& Elasticity & Correlation \\
\cline { 2 - 3 } DER & $\begin{array}{c}0.868 \\
(0.009)\end{array}$ & 0.834 \\
SIPP & & \\
All & 0.845 & 0.831 \\
& $(0.009)$ & \\
Non- & 0.867 & 0.865 \\
imputed & $(0.011)$ &
\end{tabular}

Note:

(1) Standard errors in parnethesis 
Table 5: Elasticity and Correlatation by Demographic Group

\begin{tabular}{|c|c|c|c|c|c|c|c|c|c|c|}
\hline & (1) & $\begin{array}{l}\text { (2) } \\
\text { Elas }\end{array}$ & $\begin{array}{r}(3) \\
\text { cities }\end{array}$ & (4) & (5) & (6) & (7) & $\begin{array}{c}\text { (8) } \\
\text { Correlati }\end{array}$ & (9) & $(10)$ \\
\hline & DER & SIPP & $(2)-(1)$ & SIPP NI & $(4)-(1)$ & DER & SIPP & $(7)-(6)$ & $\overline{\text { SIPP NI }}$ & (9)-(6) \\
\hline Black & 0.874 & 0.850 & -0.024 & 0.862 & -0.013 & 0.781 & 0.760 & -0.021 & 0.888 & 0.107 \\
\hline Non-Black & 0.753 & 0.738 & -0.015 & 0.916 & 0.163 & 0.836 & 0.832 & -0.004 & 0.861 & 0.025 \\
\hline Hispanic & 0.873 & 0.855 & -0.018 & 0.872 & -0.002 & 0.844 & 0.777 & -0.067 & 0.796 & -0.048 \\
\hline Non-Hispanic & 0.785 & 0.731 & -0.054 & 0.789 & 0.004 & 0.832 & 0.831 & 0.000 & 0.868 & 0.037 \\
\hline Ages & & & & & & & & & & \\
\hline 30 & 0.650 & 0.790 & 0.140 & 0.805 & 0.155 & 0.705 & 0.836 & 0.132 & 0.817 & 0.112 \\
\hline 35 & 0.814 & 0.800 & -0.014 & 0.779 & -0.035 & 0.762 & 0.854 & 0.092 & 0.871 & 0.109 \\
\hline 40 & 0.868 & 0.935 & 0.067 & 0.948 & 0.080 & 0.860 & 0.878 & 0.018 & 0.908 & 0.048 \\
\hline 45 & 0.931 & 0.782 & -0.149 & 0.816 & -0.115 & 0.895 & 0.778 & -0.118 & 0.841 & -0.055 \\
\hline 50 & 0.949 & 0.872 & -0.078 & 0.939 & -0.010 & 0.902 & 0.855 & -0.047 & 0.915 & 0.013 \\
\hline 55 & 0.975 & 0.804 & -0.171 & 0.841 & -0.134 & 0.868 & 0.749 & -0.119 & 0.815 & -0.053 \\
\hline 60 & 0.873 & 0.913 & 0.040 & 1.007 & 0.135 & 0.763 & 0.815 & 0.052 & 0.835 & 0.072 \\
\hline 65 & 1.073 & 1.167 & 0.094 & 0.998 & -0.075 & 0.936 & 0.870 & -0.066 & 0.870 & -0.067 \\
\hline cau & & & & & & & & & & \\
\hline$<12$ & 0.663 & 0.694 & 0.031 & 0.680 & 0.017 & 0.724 & 0.717 & -0.007 & 0.719 & -0.005 \\
\hline 12 & 0.849 & 0.794 & -0.054 & 0.836 & -0.013 & 0.790 & 0.790 & 0.001 & 0.850 & 0.060 \\
\hline $12-15$ & 0.877 & 0.826 & -0.051 & 0.860 & -0.017 & 0.794 & 0.804 & 0.010 & 0.830 & 0.035 \\
\hline 16 & 0.793 & 0.863 & 0.070 & 0.859 & 0.066 & 0.883 & 0.845 & -0.038 & 0.847 & -0.036 \\
\hline$>16$ & 1.004 & 0.936 & -0.067 & 1.008 & 0.004 & 0.828 & 0.784 & -0.043 & 0.881 & 0.053 \\
\hline
\end{tabular}


Table 6: Structure of Measurement Error

\begin{tabular}{|c|c|c|}
\hline & All & Non-imputec \\
\hline \multirow{3}{*}{$\boldsymbol{\beta}_{\mathbf{v}} \mathbf{E}^{*}$} & -0.339 & -0.284 \\
\hline & $(0.010)$ & $(0.011)$ \\
\hline & {$\left[\begin{array}{ll}{[} & 0.480\end{array}\right]$} & [ 0.465 ] \\
\hline \multirow[t]{3}{*}{$\beta_{\mu} E^{*(-1)}$} & -0.292 & -0.243 \\
\hline & $(0.010)$ & $(0.012)$ \\
\hline & {$\left[\begin{array}{lll} & 0.439\end{array}\right]$} & [ 0.156 ] \\
\hline \multirow{3}{*}{$\beta_{\mathbf{v \varepsilon}}$} & -0.550 & -0.533 \\
\hline & $(0.019)$ & $(0.021)$ \\
\hline & {$\left[\begin{array}{ll}{[} & 0.428\end{array}\right]$} & [ 0.477 ] \\
\hline \multirow{3}{*}{$\beta_{v \mu}$} & 0.540 & 0.482 \\
\hline & $(0.016)$ & $(0.019)$ \\
\hline & {$\left[\begin{array}{lll} & 0.487 & ]\end{array}\right.$} & {$\left[\begin{array}{lll}0.460 & ]\end{array}\right.$} \\
\hline \multirow{3}{*}{$\beta_{\varepsilon \mu}$} & 0.198 & 0.21 \\
\hline & $(0.014)$ & $(0.019)$ \\
\hline & {$\left[\begin{array}{lll} & 0.230\end{array}\right]$} & [ 0.224 ] \\
\hline
\end{tabular}

Note:

(1) Standard errors in parnethesis

(2) Correlation in brackets 
Table 7: Impact of Non-classical Measurement Error

( 1 ) DER

( 2 ) SIPP

\begin{tabular}{ccc} 
Variance & Elasticity & Correlation \\
\hline \hline 0.684 & 0.868 & 0.834 \\
0.563 & 0.845 & 0.831
\end{tabular}

\section{Counterfactual}

(3) Classical Non-classical

(4) $\quad\left(\beta_{v \mu}+\beta_{\varepsilon \mu}\right) \neq 0$

( 5 ) $\quad\left(\beta_{\left.v E^{*}-\beta_{v \varepsilon}\right) \neq 0}\right.$

(6) $\quad\left(\beta_{v E^{*}-} \beta_{\left.\mu E^{*-1}\right)} \neq 0\right.$
1.027

1.027

0.813

0.892

0.845

1.027

0.563

0.433
0.408

0.408

0.766

0.840

0.831

Notes:

Row 3 sets $\left(\beta_{v \mu}+\beta_{\varepsilon \mu}\right)=\left(\beta_{v \mathrm{E}} *-\beta_{v \varepsilon}\right)=\left(\beta_{v \mathrm{E}} *-\beta_{\mu \mathrm{E}^{*}}{ }_{(-1)}\right)=0$

Row 4 sets $\left(\beta_{v E^{*}-\beta_{v \varepsilon}}\right)=\left(\beta_{v E^{*}}-\beta_{\mu E^{*}}(-1)=0\right.$

Row 5 sets $\left(\beta_{v \mathrm{E}} *-\beta_{\mu \mathrm{E}^{*}(-1)}\right)=0$

Row 6 allows all tems to be non-zero 


\section{Table A1: DER Samples}

\begin{tabular}{ccc} 
& Full Sample & Analysis Sample \\
\cline { 2 - 3 } Log Earnings & & \\
mean & 10.440 & 10.533 \\
variance & 0.757 & 0.684
\end{tabular}

Note:

(1) Analysis sample includes only matched cases 
Figure 1:

Mean In Earnings: SIPP and DER

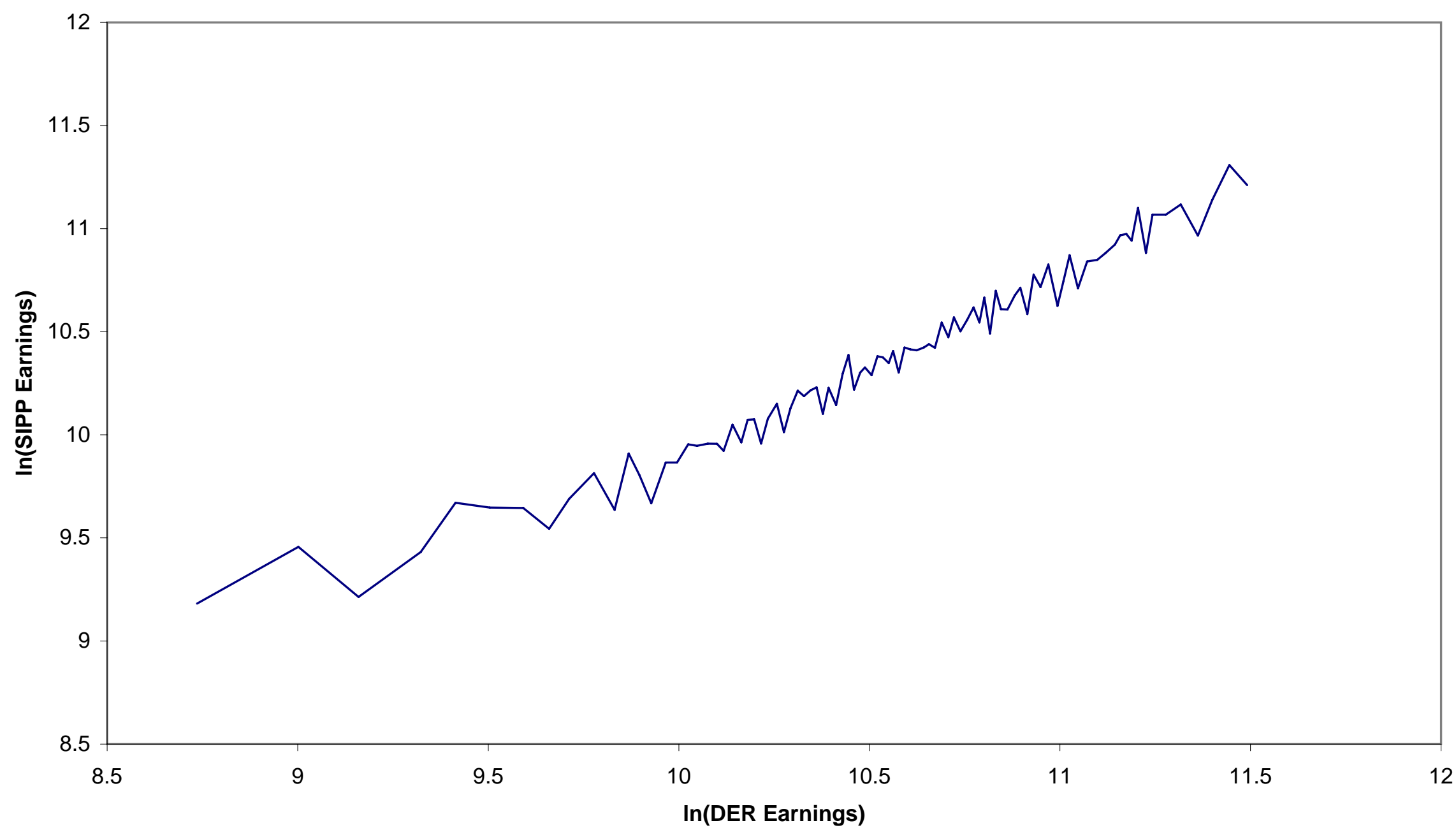


Figure 2:

DER Mean In Earnings

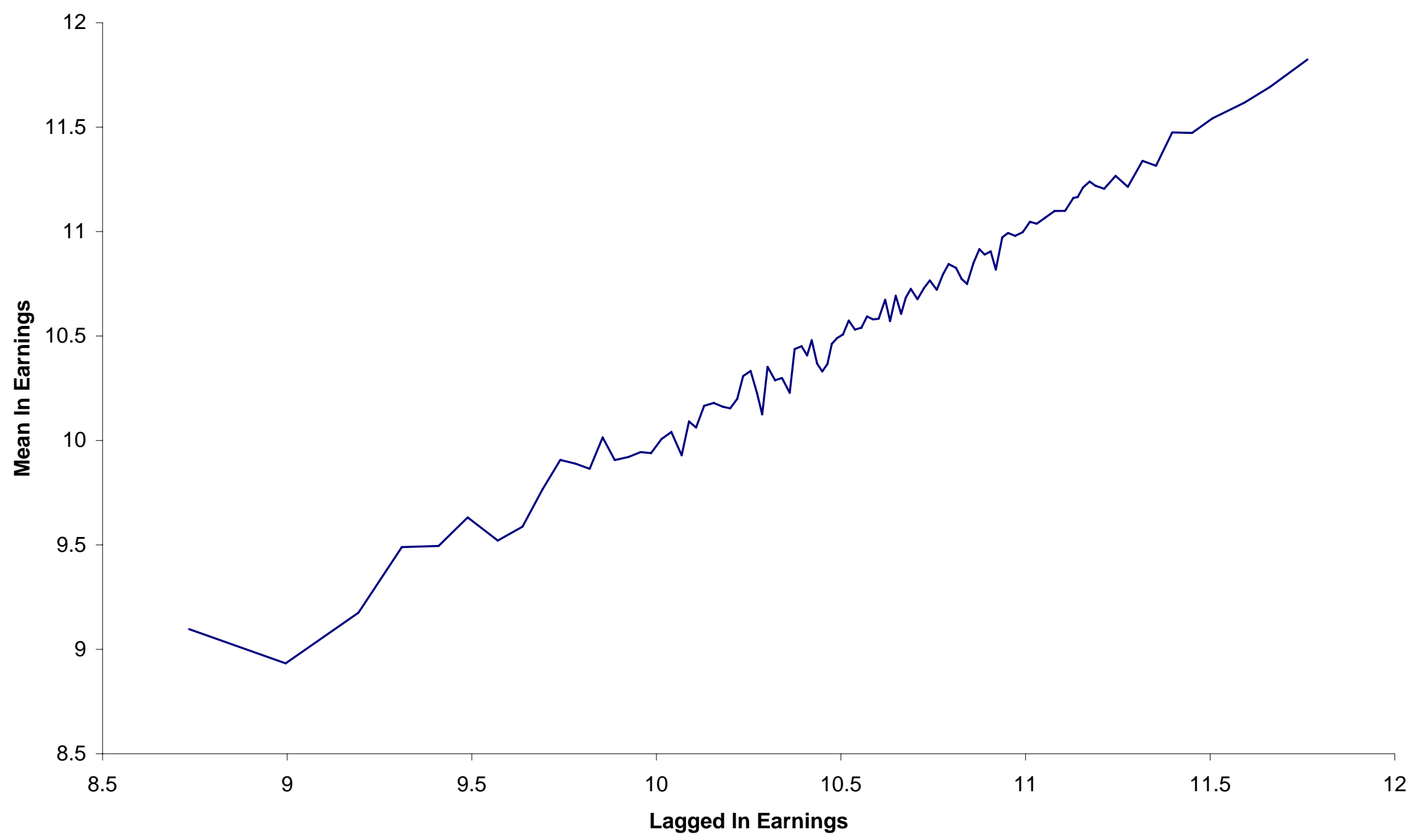


Figure 3:

SIPP Mean In Earnings

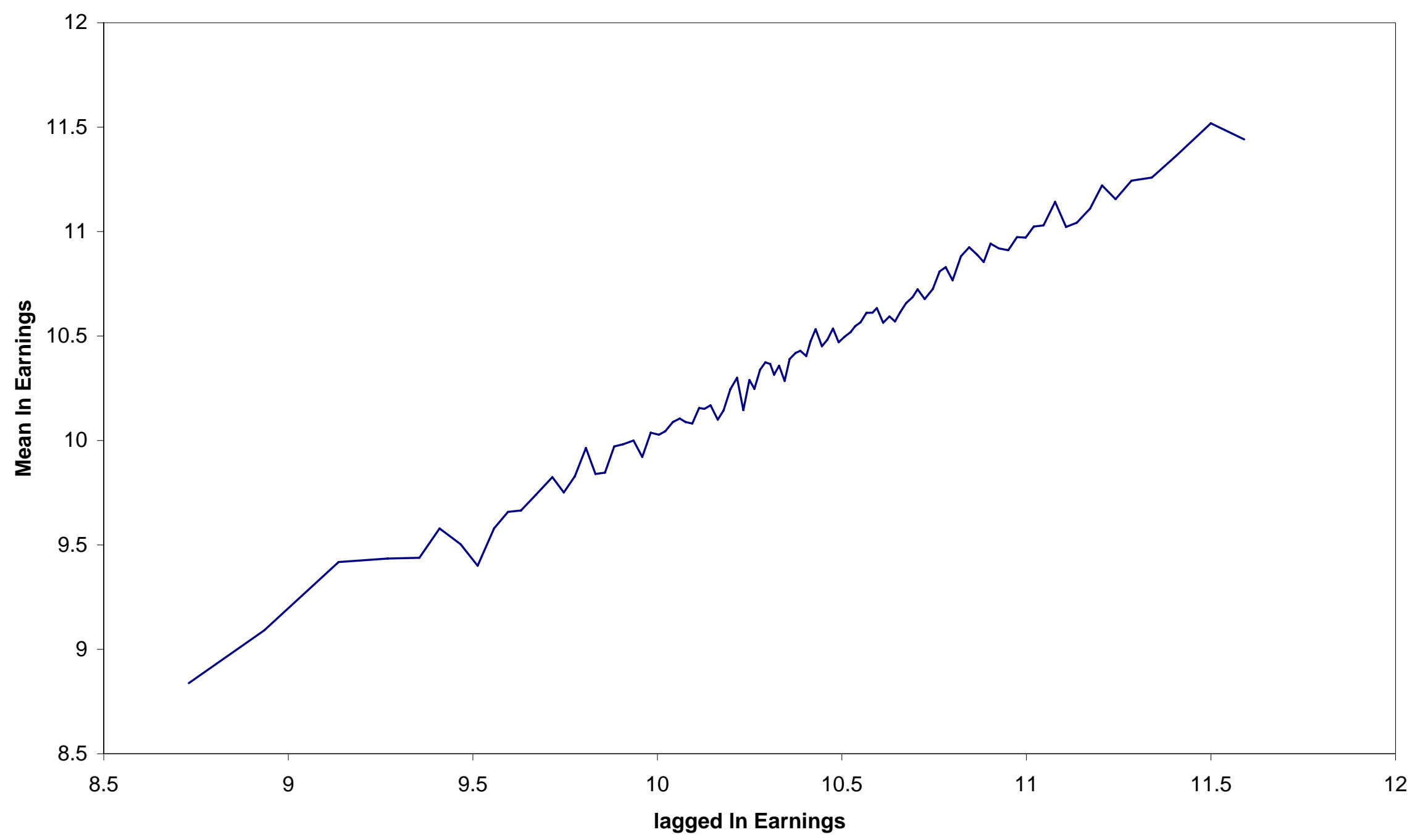


Figure 4:

Mean Reversion

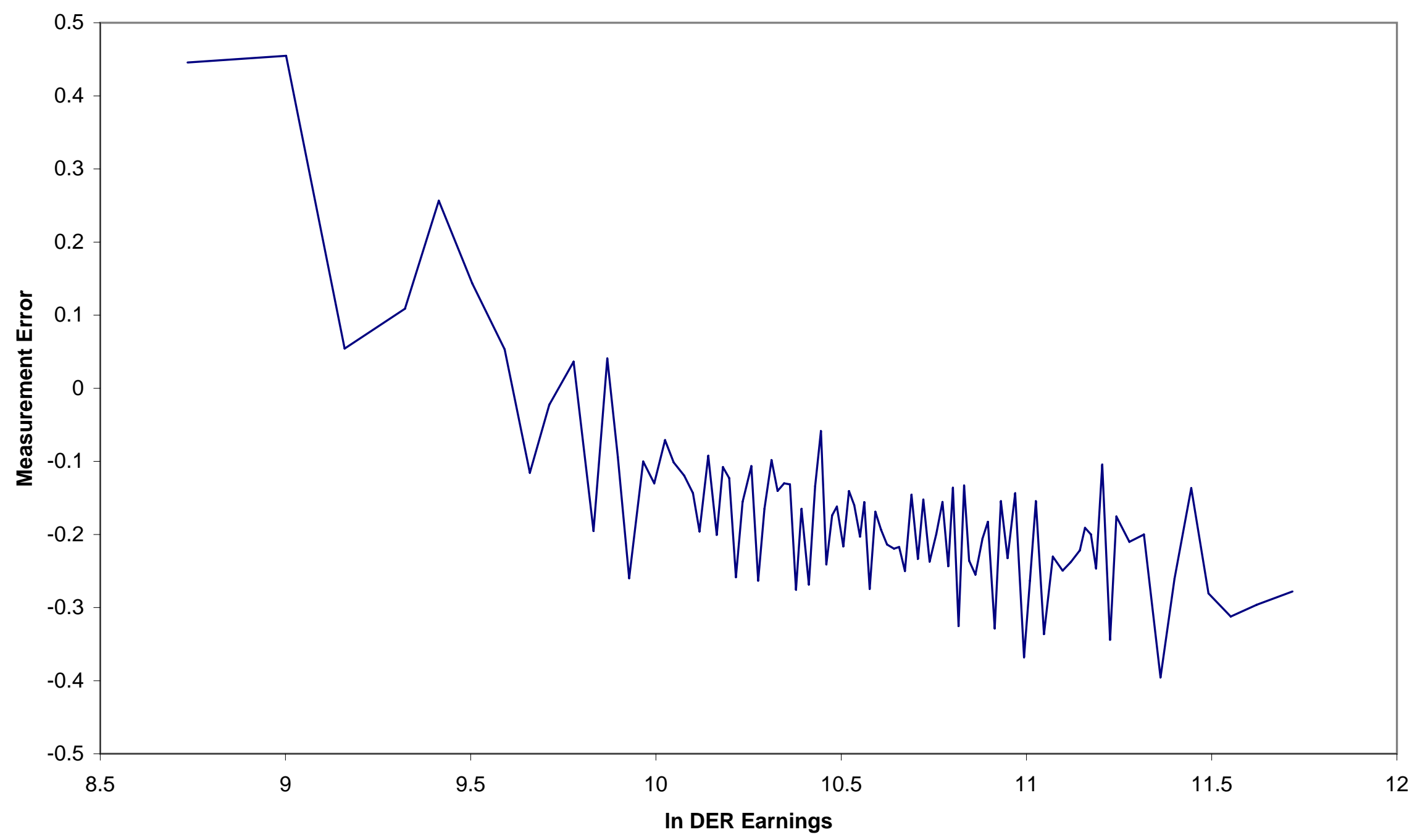


Figure 5:

Correlated Measurement Error

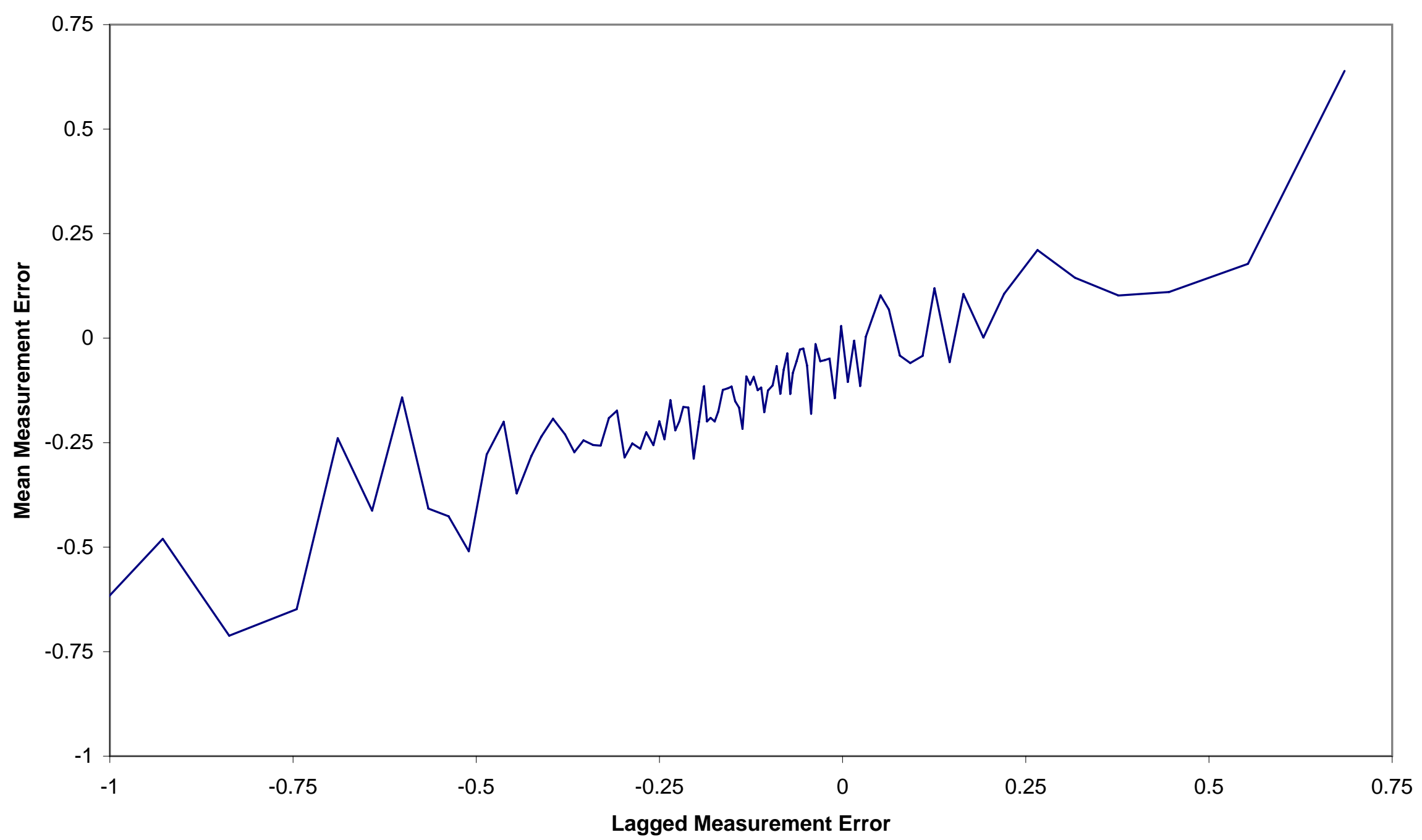

